\title{
Current perspectives on the optimal management of infantile hemangioma
}

This article was published in the following Dove Press journal:

Pediatric Health, Medicine and Therapeutics

\section{Peter Grzesik June KWu}

Department of Surgery, Columbia University College of Physicians and Surgeons, New York, NY, USA
Correspondence: June K Wu Department of Surgery, Columbia University College of Physicians and Surgeons, 16I Fort Washington Avenue, Suite 5I I, New York, NY 10032, USA Tel + I 2/23423704

Email jw92@cumc.columbia.edu

\begin{abstract}
Infantile hemangiomas (IHs) are the most common benign tumor of infancy. As our understanding of their pathobiology has evolved, treatment has become more focused and tailored to specifically treat IH while minimizing adverse effects. Propranolol has gained FDA approval as the first medical therapy for a traditionally surgical disease. This review provides readers with an overview of $\mathrm{IH}$, treatment modalities, and addresses specific considerations in IH disease management.
\end{abstract}

Keywords: infantile hemangioma, medical treatment indications, propranolol, complications of infantile hemangioma

\section{Introduction}

Infantile hemangiomas (IHs) are the most common benign tumor of infancy ${ }^{1-3}$ with an incidence of approximately 4-5\%. ${ }^{2,4}$ It is more common in females and Caucasians. ${ }^{4,5}$ IHs are also associated with low birth weight and premature infants. ${ }^{5-7}$ Preterm infants have an increased incidence of developing IHs and can be as high as $30 \%$ in infants with birth weight $<1000$ g. ${ }^{6,8}$ Other risk factors associated with IH development include placental abnormalities ${ }^{5,9-11}$ and infants whose mother underwent either amniocentesis or chorionic villus sampling. ${ }^{11-13}$ However, none of these factors have been proven to have a causal relationship with IH development.

Preterm infants have been shown to have an increased incidence of IHs that is associated with birth weight. ${ }^{6}$ The incidence of $\mathrm{IH}$ is increased with decreasing gestational age with a female and Caucasian predominance. ${ }^{8}$

IHs have a distinct natural history involving 3 stages. An early proliferative phase is characterized by rapid growth of abnormal blood vessels during the first 6 months of life and extends to the first 10-12 months of life. The hemangioma appears bright red and bosselated (Figure 1). This proliferative phase is followed by an involuting phase starting at about 1 year of age and can take years for complete involution., ${ }^{2,4}$ An involuted IH may shrink resulting in anetoderma of the involved area. Otherwise, an involuted $\mathrm{IH}$ can result in a fibrofatty residuum with contour deformity (Figure 2).,14-16 Coarse telangiectasia can also be seen on the skin surface. ${ }^{4,16,17}$ Although IHs are benign and undergo spontaneous regression, ${ }^{18}$ their clinical course during any phase, but in particular during the proliferative phase, can lead to significant morbidity and mortality to patients. Intervention is indicated if the $\mathrm{IH}$ is expected to cause morbidities. 


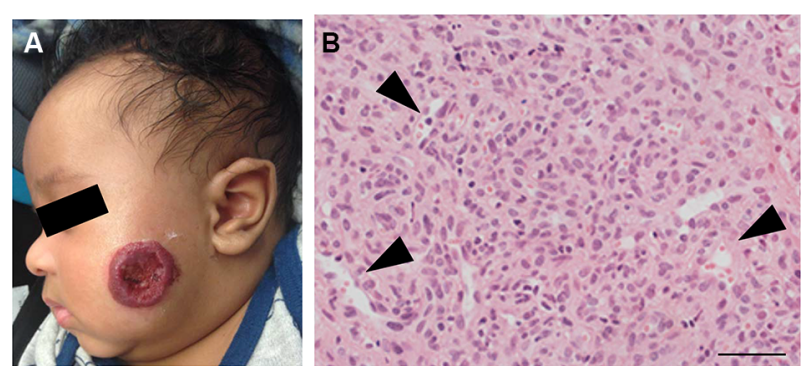

Figure I (A) A proliferating IH on the cheek of an infant. Note the ulceration in the center of the $\mathrm{IH}$. (B) A proliferating $\mathrm{IH}$ is highly cellular with poorly defined vascular spaces (black arrowheads).

Note: Magnification of image B, $40 \times$; scale bar $=50 \mu \mathrm{m}$.

Abbreviation: $\mathrm{IH}$, infantile hemangioma.

A
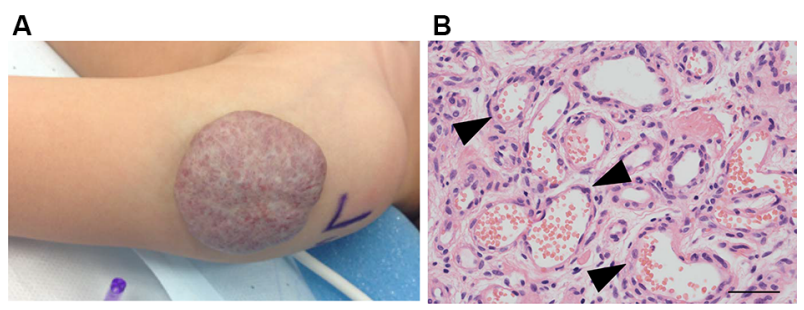

Figure 2 (A) An involuting IH on the arm of a toddler. Note the graying red color when compared to the proliferating $\mathrm{IH}$. (B) Histology: involuting $\mathrm{IHs}$ have fewer cells and organized vascular tubular structures (black arrowheads).

Note: Magnification of image B, $40 \times$; scale bar $=50 \mu \mathrm{m}$.

Abbreviation: $\mathrm{IH}$, infantile hemangioma.

\section{Morbidities associated with IHs}

Despite being a "benign" tumor with eventual involution and possible resolution, IHs can develop complications and require medical intervention. One study reports $24 \%$ of patients presented with a complication and $38 \%$ of patients required treatment. ${ }^{7}$ Different morbidities are associated with proliferative phase versus involuting/involuted phase IH. Therefore, the treatment modalities may be different based on the morbidity that has developed. However, the timing of intervention may or may not correlate with the time that a morbidity has developed. For example, an urgent ulceration or bleeding of a proliferating $\mathrm{IH}$ will require intervention at the time of development of the complication. By contrast, a large IH that results in a residual contour deformity can be treated more electively, with less urgency to immediate intervention.

\section{Proliferative phase}

Morbidities during proliferation include ulceration, bleeding, and obstruction of vital structures. Surgical biopsy may be indicated in the case of a diagnostic dilemma. In particular, preterm infants have an increased risk of ulceration of their IHs. ${ }^{19}$ In fact, preterm birth predisposes infants to ulceration of IHs, with an odds ratio of 2.29. ${ }^{19}$

\section{Involuting/involuted phase}

During the involuting/involuted phase, the major morbidities are disfigurement and contour deformity. If there was ulceration that healed secondarily, there will be disfigurement from the residual scar.

\section{Hepatic hemangiomas $(\mathrm{HHs})$}

A special subset of IHs are visceral IHs, of which HHs are the most common. ${ }^{20-22}$ There are 3 subtypes of HHs: solitary, multifocal, and diffuse. Only the multifocal HHs are similar to IHs. HH lesions in some patients had similarities to both multiple and diffuse HHs, suggesting that there is a link between multifocal and diffuse $\mathrm{HH}{ }^{23}$ The solitary $\mathrm{HH}$ is thought to be similar to a congenital hemangioma, whereas a diffuse $\mathrm{HH}$ would almost completely replace liver parenchyma, and the infant may develop abdominal compartment syndrome and severe hypothyroidism. Affected infants can develop high out cardiac failure from shunting as well. These can be life-threatening conditions.

\section{Indications for treatment Proliferative phase}

There are few indications for treatment during the proliferative phase. They are divided into the broad categories of 1) prevention of, or limitation of extent, of morbidities, and 2) treatment of morbidities that have already developed.

\section{Prevention of morbidities}

Systemic medical therapies are indicated to prevent the development of morbidities associated with both proliferative and involuting/involuted phase morbidities. Medical therapies are also indicated as a treatment modality even after the development of some morbidities. ${ }^{24}$ If the IH is located in an anatomically sensitive area, such as the face, or if rapid proliferation leading to disfigurement is expected, or if there are concerns for potential functional impairment if the IH growth is left unchecked, then medical therapy is indicated. ${ }^{25}$ The goal of medical therapies is to prevent or limit IH proliferation to decrease the risk of ulceration/bleeding, or the subsequent disfigurement that may result without intervention.

\section{Common morbidities and diagnostic dilemma}

Treatment is indicated for ulceration ${ }^{18,24,26}$ (Figure 1) and bleeding. ${ }^{15,27}$ Ulcerated IH may require wound care with or without concurrent medical therapies, and antibiotics may be needed if there is superinfection. Laser therapy may improve healing time and decrease pain. ${ }^{28}$ Refractory ulceration nonresponsive to conservative management may require surgical 
resection and closure. Oozing may occur with an ulcerated $\mathrm{IH}$ and will stop after replacement of a dressing. Occasionally, arterial bleeding can occur with or without concurrent ulceration. These are true surgical emergencies, and the source of bleeding - the IH - needs to be surgically resected. ${ }^{15,27}$

Less commonly, an IH may present with less typical feature. If the natural history or imaging modalities are not completely consistent with an IH, and there are concerns of a different lesion in the differential diagnosis, excisional or incisional biopsy may be indicated. Differential diagnoses include a wide range of benign and malignant lesions, including glioma (glabella IH), other vascular tumors such as tufted angiomas, hemangiopericytoma, and kaposiform hemangioendothelioma (KHE), vascular malformations such as venous and lymphatic malformations, to malignant lesions including infantile fibrosarcoma, rhabdomyosarcoma, and neuroblastoma. ${ }^{25}$

\section{Special considerations: airway and subglottic IHs}

Subglottic IHs may obstruct the airway. Infants do not usually present until the $\mathrm{IH}$ has proliferated large enough to produce biphasic stridor. ${ }^{29,30}$ If an infant presents with a beard distribution $\mathrm{IH}$, there is a high risk $(>60 \%)$ for a concurrent subglottic IH. ${ }^{31,32}$ Patients with beard distribution IH should be investigated by fiberoptic bronchoscopy. The patient may require multimodality treatments including medical, laser, and surgical therapies.

\section{Special considerations: periorbital IHs}

Periorbital IHs may obstruct the visual axis. ${ }^{33,34}$ If left untreated, astigmatism can occur as a result of deformation of the cornea from pressure exerted by an upper eyelid IH. Deprivation amblyopia can occur from a large periorbital $\mathrm{IH}$ obstructing input to the retina at a critical period of development of the visual axis. If the IH is untreated, permanent blindness in the affected eye will result. Medical and/or surgical treatment is indicated. Every infant who develops a periorbital IH should be referred to a pediatric ophthalmologist for evaluation and management as well.

\section{Special considerations: PHACE syndrome}

PHACE syndrome was first described in 2005 and consists of a Posterior fossa brain malformations, large segmental facial Hemangioma, Arterial anomalies, Cardiac anomalies, and Eye anomalies. ${ }^{2,35,36}$ The central nervous system (CNS) abnormality has since been defined to include other structure brain anomalies not limited to the posterior fossa. ${ }^{36}$ Arterial anomalies include atresia or absence of the ipsilateral cerebral circulatory system. These patients are at risk for ischemic infarcts. ${ }^{35,37-39}$ PHACE syndrome is diagnosed when 2 or more major criteria are met. ${ }^{40}$ When a patient presents with a large segmental facial $\mathrm{IH}$, there is $\sim 20 \%$ risk of PHACE syndrome. ${ }^{41}$ Interventions unrelated to the hemangiomas may be indicated for these patients. For example, cardiac surgery may be indicated if there is coarctation of the aorta ${ }^{42}$ or a encephaloduroarteriosynangiosis, where the superficial temporal artery is grafted directly onto the pia mater of the CNS, which may be indicated to provide adequate perfusion to the brain. ${ }^{38,43}$

\section{Special considerations: $\mathrm{HH}$}

There are 3 subtypes of HH: solitary, multifocal, and diffuse. The solitary $\mathrm{HH}$ is thought to be a rapidly involuting congenital hemangioma and will resolve without intervention and is often an incidental finding. The multifocal $\mathrm{HH}$ has glucose transporter 1 (GLUT1) positivity and is thought to be similar to IHs. Multifocal HHs do not always have physiological symptoms but are thought to respond to propranolol or corticosteroids. Diffuse HH can be life-threatening. Liver parenchyma is almost completely replaced by $\mathrm{HH}$, resulting in hepatomegaly, compression of the vena cava, abdominal compartment syndrome, high output cardiac failure from shunting, and severe, life-threatening hypothyroidism from the production of type 3 iodothyronine deiodinase by the $\mathrm{HH} .{ }^{20-22}$

\section{Involuting/involuted phase}

During the involuting/involuted phase, the indication for treatment is to treat residual stigmata. Laser and surgical treatments are the main modalities. If there is coarse telangiectasia, laser therapy is indicated..$^{44,45}$ If the elasticity of the skin is destroyed, anetoderma results. ${ }^{16}$ This can be treated with surgical resection if it is clinically obvious. If there is gross disfigurement resulting from rapid proliferation resulting in contour deformity, then surgical resection and debulking are the only treatment options. All surgical treatment options will result in scars. Therefore, the objective is to produce a scar that is more esthetically pleasing than the deformity.

\section{Treatment modalities: during the proliferative phase Laser}

Laser treatment has been shown to be efficacious in correcting discoloration. ${ }^{44,45}$ A hypothesis has developed that laser treatment in the early proliferative phase, before the bulk develops and IH thickens, may contain and disrupt IH 
proliferation. Unfortunately, a randomized controlled trial demonstrated that early laser treatment was unable to prevent IH proliferation, although it did treat children who had more skin atrophy and hypopigmentation. ${ }^{46}$ Therefore, there are no indications for laser treatment for discoloration during the proliferative phase, and early treatment may have less desirable esthetic appearances of the skin.

However, there is a role for laser treatment to improve ulceration. ${ }^{47,48} \mathrm{~A}$ dual wavelength pulsed dye laser (PDL) can be used. Laser treatment resulted in more rapid healing of the ulcer and decreased pain. ${ }^{28}$

Another role for laser therapy during proliferation is for the treatment of airway hemangiomas. If a large subglottic IH obstructs the airway, and medical treatment alone is not sufficient, resection using laser is the treatment of choice. Unlike laser treatments for the superficial aspects of $\mathrm{IH}$, laser treatment of airway IHs use ablative lasers such as $\mathrm{CO}_{2} \cdot{ }^{49,50}$ Other ablative lasers have also been used, such as the potassium titanyl phosphate (KTP) laser ${ }^{51}$ and the Nd:Yag laser. ${ }^{52}$ However, it is important to note that an obstructing subglottic hemangioma is potentially life-threatening, and it is common to treat with multiple modalities, including medical therapy, and laser ablation.

\section{Medical therapy}

The most common treatment modality during the proliferative phase is medical treatment. Medical intervention is indicated when an IH is in an anatomically critical area, and rapid proliferation can cause destruction and/or obstruction and ulceration. ${ }^{53}$ The goal is to limit or disrupt the IH proliferative process, to either minimize or prevent development of morbidities altogether. Effective medical treatment during proliferation could minimize or prevent the future need for surgical debulking and recontouring (subsequently). If an $\mathrm{IH}$ is not expected to proliferate to the extent to cause significant disfigurement, or if an IH is small, or in an anatomically noncritical area (trunk, arm, and leg), and expected to have no lasting sequelae after involution, it is acceptable to monitor conservatively with no intervention. ${ }^{25}$

\section{Propranolol}

Propranolol is now considered the first-line medical treatment. Hemangeol $\AA$, a liquid formulation of propranolol, obtained FDA approval for the treatment of IH in March 2014. This was the first time that a medication was approved for the treatment of any type of infantile vascular tumor.

Propranolol efficacy was first discovered when 2 infants with large IHs had signs of cardiac failure. Propranolol was initiated for their cardiac indications, but the IHs regressed rapidly. ${ }^{54} \mathrm{~A}$ subsequent follow-up study confirmed a response rate of $100 \%$ in 32 patients. ${ }^{55}$ Since the first reports, there have been multiple small series and case reports of propranolol efficacy. ${ }^{56-59}$ A meta-analysis demonstrated that propranolol was more effective than laser, steroids, and vincristine. ${ }^{60}$

The first randomized controlled trial for propranolol demonstrated propranolol efficacy in the discoloration and volume as early as 4 weeks after treatment initiation. However, the authors reported rebound growth if treatment was stopped before the patient turned 1 year of age. ${ }^{61}$ Infants with PHACE syndrome were excluded. Subsequent large-scale studies, including a meta-analysis of 1264 patients, demonstrated a response rate of $82-100 \%$, rebound growth in $17 \%$ of patients, and adverse event incidence of $31 \%$, although the majority were minor, including sleep disturbances and acrocyanosis. Serious adverse events were noted in $<1 \%$ of patients $(10 / 1264)$ and included bradycardia, hypoglycemia, and hypotension. ${ }^{62}$

Established guidelines on the initiation and management of infants on propranolol have been established. ${ }^{53}$ These included cardiology evaluation (if available) and baseline EKG prior to dose initiation. Heart rate and blood pressure are monitored after every dose escalation. Frequent feeding has been recommended to prevent hypoglycemia. The goal dose is usually $2 \mathrm{mg} / \mathrm{kg} /$ day in divided doses (twice a day [BID] or thrice a day [TID]). ${ }^{53}$ While some have questioned the lack of evidence in the safety of using propranolol in preterm infants, ${ }^{8}$ others have demonstrated that preterm infants can have a good response to and statistically significant response to propranolol versus to term infants. ${ }^{63}$ Additional investigation is needed to definitively establish a treatment regimen for $\mathrm{IH}$ in preterm infants.

PHACE syndrome is not a contraindication to propranolol treatment. PHACE patients were further subdivided into "standard risk" and "high risk" groups, with "standard risk" patients in the same risk stratification as non-PHACE patients. ${ }^{53}$ Thirty-two patients with PHACE syndrome - some considered high risk - were treated with propranolol, and only 1 patient was reported to have a reversible neurological sequelae - mild hemiparesis that improved during propranolol treatment. Nevertheless, extreme caution should be exercised when treating a PHACE patient with propranolol. ${ }^{64}$

There have been anecdotal reports of using other types of beta-adrenergic receptor blocker for treatment, ${ }^{65,66}$ but their superiority to propranolol has not been demonstrated. Topical timolol has gained popularity as a low-risk alternative to treat smaller IHs. ${ }^{67}$ However, it does not penetrate deeper, bulkier IHs. 


\section{Corticosteroids}

Prior to the discovery of propranolol, corticosteroids were the first-line medical therapy for problematic IHs. Systemic corticosteroid therapy has traditionally been one of the mainstays of treatment in IH. This novel treatment was discovered after systemic steroid therapy was started for the treatment of thrombocytopenia in a child with a hemangioma to prevent further hemorrhagic episodes. The hemangiomas were noticed to become visibly smaller. ${ }^{68}$

A study by Pope et al ${ }^{69}$ evaluated the effectiveness of oral versus high-dose pulsed corticosteroids in the treatment of problematic facial IH. In this study, 20 patients were divided into 2 treatment groups, with the oral group receiving prednisolone $2 \mathrm{mg} / \mathrm{kg} / \mathrm{day}$ in 2 divided doses for 3 months followed by a taper schedule over 6-9 months to prevent rebound. The high-dose pulsed group received pulses of intravenous (IV) corticosteroids monthly for 3 months. The pulse consisted of methylprednisolone $30 \mathrm{mg} / \mathrm{kg}$ per day for 3 days. The patients were evaluated at 3 months and 1 year. At the 3-month mark, the patients treated with oral therapy had an improvement in the visual appearance (using a visual analog scale) of the IH versus the IV therapy $(P=0.002)$ as well as the 1-year mark with a greater improvement in the visual appearance of the oral treatment groups versus IV therapy $(P=0.005)$. Interestingly in the study, they evaluated 4 angiogenesis markers, plasma bFGF, VEGF, VCAM-1, and endoglin, and urinary bFGF prior to treatment and every month for the first 3 months in a subset of both study groups. VCAM-1 $(P<0.001)$ and endoglin $(P=0.03)$ decreased significantly overtime while the others did not change over the study. ${ }^{69}$

A recent study by Greene et al treated 25 patients with problematic IH that involved the head and neck with $3.0 \mathrm{mg} /$ $\mathrm{kg} /$ day of oral prednisolone for 1 month followed by a $0.5 \mathrm{~mL}$ taper every 2-4 weeks until discontinuation when the patient reached 10 months of age. All IHs responded to treatment and $88 \%$ showed regression and $12 \%$ stabilized in growth. ${ }^{14}$ The Greene et al study showed a rebound growth rate of $8 \%$ that was managed successfully by increasing the dosage of prednisolone by $0.5 \mathrm{~mL}$ for 1 month before weaning off steroids again.

The long-term side effects of corticosteroid therapy are well established..$^{70,71}$ Some of which are gastric ulcers, osteoporosis, increased risk of heart disease, increased risk of infections, easy bruiseability, wound complications, glucose intolerance, and hypertension. A study by Boon et $\mathrm{al}^{72}$ identified 80 infants treated with steroids for IHs. Seventy-one percentage of infants developed Cushingoid facies, $42 \%$ had a decrease in growth in their weight curve, $35 \%$ fell below their growth curve for height, $29 \%$ of parents reported irritability, $21 \%$ had gastric irritation, and $6 \%$ developed oral and/or perineal yeast infection that necessitated antifungal therapy. However, these effects were reversed after cessation of corticosteroid treatment. ${ }^{72}$ This study highlights some of the potentially serious short-term complications associated with systemic corticosteroid therapy. The authors concluded that oral steroid therapy at a dose of $2-3 \mathrm{mg} / \mathrm{kg} /$ day for 1 month and then tapered seem to be safe for the treatment of problematic hemangiomas.

More recently, a randomized clinical trial directly comparing corticosteroids to propranolol demonstrated similar efficacy for corticosteroids and propranolol. The frequency of adverse events (AEs) was also comparable, although the corticosteroid group had more severe AEs. Rate of rebound growth was also comparable. The authors concluded that both medications had similar response rate but corticosteroids resulted in a faster response time, while propranolol was better tolerated. ${ }^{73}$

In conclusion, these studies demonstrate that corticosteroids may still have a role in medical management. Propranolol has received FDA approval and should be used as a first-line treatment; if propranolol is contraindicated, corticosteroids should be considered.

\section{Interferon}

Interferon is included in this discussion as a historical interest. The exact mechanism for corticosteroid and propranolol efficacy is not completely understood; both were discovered serendipitously. However, as IHs are vascular tumors and thought to have proliferation of abnormal vasculature, interferon was proposed to be used as an antiangiogenic agent. Early success in the treatment of a patient with pulmonary hemangiomatosis with interferon encouraged the use of this medication. ${ }^{74,75}$ In a 1991 study by Ezekowitz et al, ${ }^{76}$ 13 patients with either life-threatening coagulopathy or sight-threatening hemangiomas were treated with interferon alpha after failing steroid therapy. Regression was achieved in 11 of the 13 patients and 3 out of 4 for steroid resistant coagulopathy with little or no toxicity observed at a dose of 2 million units $/ \mathrm{m}^{2}{ }^{76}$ Interferon alpha therapy was thought to be an improvement over steroids for the treatment of lifethreatening hemangiomas.

However, this early enthusiasm was tempered by adverse effects of interferon. Effects of systemic interferon therapy are commonly associated with fever, leukopenia, elevation of serum transaminase levels, as well as some CNS toxicity 
usually manifested by drowsiness or confusion. ${ }^{77}$ However, the most serious side effect of interferon was irreversible spastic diplegia, a form of hypertonicity and spasticity predominately in the lower extremities. ${ }^{78}$ The risk of developing spastic diplegia was $19 \%$, and $3 / 5$ patients developed irreversible spastic diplegia. Due to this severe adverse effect, interferon is not used to treat IHs.

\section{Vincristine}

Vincristine has been used to treat HHs when corticosteroids have failed., ${ }^{4,56,79}$ However, since propranolol has demonstrated efficacy in hepatic IHs as well, ${ }^{80}$ vincristine has become a second-line therapy for hepatic IHs.

\section{Surgical therapy}

Unlike during the involuting/involuted phase, there are very few indications for surgical intervention during proliferation. One indication is for confirmation of diagnosis. There are other mimickers of $\mathrm{IH}$, and some of them are malignant lesions. ${ }^{25,81}$ Therefore, if the clinical history, physical examination, and/or imaging studies are not consistent with $\mathrm{IH}$, and there are concerns that the lesion is not an $\mathrm{IH}$, incision or excisional biopsy is indicated to ascertain the diagnosis. IHs have GLUT1+ vessels, and positive GLUT1 staining is diagnostic of IH (Figure 3). ${ }^{82}$

A rapidly proliferating IH can erode the overlying epidermis and cause arterial bleed. This is one of the few absolute indications for surgical resection. ${ }^{15,27}$ A relative indication for surgical resection during proliferation is ulceration refractory
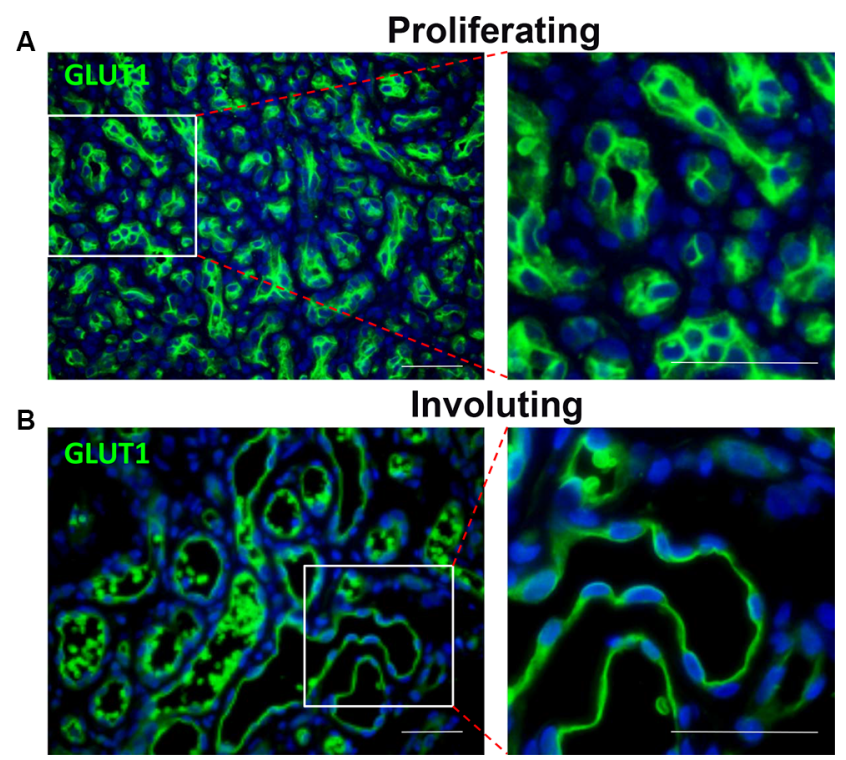

Figure 3 Both proliferating (A) and involuting (B) IH endothelial cells express GLUTI (green).

Notes: Magnification, 40x; scale bars $=50 \mu \mathrm{m}$. Right column indicates close-up views. Abbreviations: IH, infantile hemangioma; GLUTI, glucose transporter I. to conservative treatment. An ulceration will ultimately result in a large scar. Until reepithelialization (healing of the ulcer) occurs, the area is tender and at risk for superinfection. If possible, the IH can be resected en bloc. However, if the IH is too large for resection and closure, a partial debulking can be performed, and the rest of the IH can be sutured to each other. The remaining IH can heal and be treated as any non-ulcerated IH.

IHs are comprised of a growth of abnormal vasculature; this is surrounded by an avascular fibrous layer. There are multiple feeding vessels that supply the IH, commonly from the deep surface. Therefore, the surgical approach for cutaneous IHs should be to make the skin incision and separate the IH tissues from the surrounding normal tissues at this avascular fibrous plane. This dissection can even be performed with sharp iris scissors. Feeding vessels should be carefully isolated, cauterized, and divided (Figure 4). ${ }^{83}$

\section{Supportive and other adjuvant therapy}

As mentioned earlier, other supportive and adjuvant therapies may be indicated. If an airway $\mathrm{IH}$ is refractory to interventions, or an airway cannot be securely established, a tracheostomy may be indicated in the most severe cases. In periorbital IHs, an ophthalmologist may prescribe patching or other treatments to correct visual defects. In the case of PHACE syndrome, depending on the associated anomalies, the patient may need consultations and management by cardiology and neurology. ${ }^{38,42}$ A similar syndrome, PELVIS syndrome, involves hemangiomas in the sacral/perineal area associated with underlying anomalies in the genitourinary systems. ${ }^{84}$ These patients may need consultations with and management by urologists.

Diffuse HH can be life-threatening. Patients can develop high output cardiac failure from shunting. ${ }^{21,22}$ In diffuse
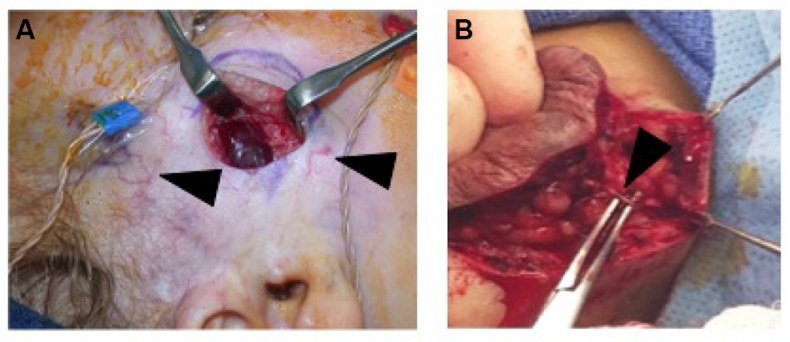

Figure 4 (A) Intraoperative photo demonstrating that IH can be easily separated from the surrounding soft tissue. Note facial monitoring devices in place. These can be used to assist during facial dissection. Course telangiectasia can be seen as well (arrowheads). (B) Feeding vessels to the IH need to be identified (black arrowhead) and isolated before dividing to minimize blood loss.

Abbreviation: $\mathrm{lH}$, infantile hemangioma. 
hepatic IHs, patients may also develop severe and lifethreatening hypothyroidism, due to production of type 3 iodothyronine deiodinase in the $\mathrm{IH}^{20,21}$ Management and replacement of thyroid hormones are essential. In severe cases, liver transplantation may be life-saving. ${ }^{21,22}$

\section{Treatment modalities: during the involuting/involuted phase}

The major morbidities associated with involuting/involuted IH are contour irregularities and disfigurements from a large IH. If there are contour deformities, the only treatment option is surgical debulking and recontouring of affected areas. There is a small role for laser therapy.

\section{Laser}

Laser therapy may be indicated to correct persistent coarse telangiectasia without contour irregularities after IH involution. Laser therapy in IH works by inducing injury to the vasculature. ${ }^{85}$ Lasers only penetrate into the dermis and thus will not have an effect on contour deformity. The main type of laser for color correction is the PDL. ${ }^{17,28,44}$ It is the first laser specially designed to treat vascular lesions without producing a scar. ${ }^{71}$ The PDL is characterized by selective destruction of blood vessels by matching the wavelength of light absorbed by hemoglobin. ${ }^{71}$ The average depth of penetration of PDL is $0.8 \mathrm{~mm}^{86}$ and thus will not affect deeper components of IHs, such as the bulk. The PDL has become the laser of choice for superficial hemangiomas because treatment is relatively simple and complications are rare. ${ }^{44,87}$

The persistent discoloration from an involuting/involuted $\mathrm{IH}$ is usually resected during recontouring procedures. However, on occasion, if surgical debulking is used only to address the abnormal contour, some residual discoloration may remain. The treatment options are to enlarge the area of resection to include all discolored skin (thus leaving a larger permanent scar for the patient) or to resect the minimal area with contour deformity and leave discolored but normal contour IH residuum for laser therapy. This combination approach is preferred by the authors to minimize permanent scarring.

\section{Medical therapy}

While propranolol treatment has demonstrated efficacy in treating involuting IHs, there are limited indications to treat IHs beyond the proliferative phase, as the potential benefits to accelerate involution must be weighed against the potential morbidities and inconvenience of using propranolol. ${ }^{88}$

\section{Surgical therapy}

Surgical therapy is the main treatment modality for involuting/involuted IH disfigurement. The goal of the treatment is to remove inelastic, abnormal skin (anetoderma), heal ulceration scar, and to recontour the affected area. It is important to note that the fibrofatty residuum may have already replaced some of the normal subcutaneous tissues. Therefore, complete removal of the IH fibrofatty residuum may not be desirable, as it will leave an atrophic defect.

Another goal is to minimize the size of the scar. In the forehead and cheek, a purse-string closure may be preferable. ${ }^{89,90}$ The abnormal skin is excised at the base resulting in a circular type of defect. The textbook teaching will require that a 3:1 length-to-width lenticular scar be created to close without skin puckering. ${ }^{89}$ This will result in a $>3 \times$ lengthening of the scar. Furthermore, the tension will be bidirection. It may distort surrounding features, such as eyebrows, commissure, or palpebral fissure. A purse-string closure on the other hand will not require further lengthening of the scar. The purse-string will actually contract and minimize the scar. The circumferential and equal distribution of tension will also minimize distortion of surrounding structures. The major drawback is that it will result in a widened, albeit smaller circular or ovoid scar. This can be secondarily revised. The purse-string closure method will result in the smallest possible scar. ${ }^{89,90}$ It should be avoided in high tension, or otherwise easily closed areas, such as the neck and the scalp. The parents should be counseled that there will be a scar from debulking. However, the resulting scar will be less obvious and more esthetically pleasing than $\mathrm{IH}$ deformity. If the $\mathrm{IH}$ deformity is so subtle that a scar is not expected to be less conspicuous than the deformity, then surgical intervention is not indicated at all.

A retrospective study on surgical treatment of IH has found that a disproportionate amount of IH requiring surgical debulking occurs on the head and neck, even higher than the normal head and neck distribution of IH occurrence. ${ }^{15}$ Furthermore, the average size of the deformity is smaller in the head and neck IH, compared to those below the neck, further supporting that head and neck IHs cause disproportionately more disfigurement that require intervention.

\section{Special consideration: lip}

IHs on the lip may distort the lip in multiple dimensions: the transverse, cephalad-caudad, as well as the anterior-posterior axes. Therefore, it is not expected that 1 operation will easily and completely restore the normal contour, and a staged 
approach may be required..$^{91}$ The goal will be to decrease or normalize 1 or 2 dimensions at each stage. If the IH does not cross the vermilion-cutaneous border, a staged approach can allow debulking and recontouring without extending a scar onto the face. If the vermilion-cutaneous border is crossed, every effort should be made to minimize the scar on the skin if possible, ${ }^{91}$ and if it is not possible to limit the skin resection only to the abnormal skin from IH disfigurement.

A 1-stage approach can also be used, but this will require extending the scar into the skin. ${ }^{92}$ As scars are permanent every effort should be made to minimize obvious scarring if possible.

\section{Special considerations: nose}

\section{Nasal dorsum}

If the nasal skin is stretched and abnormal, they will need to be resected as well and there will be an unavoidable scar. If possible, the incision should be designed to align with the borders of the nasal subunits to make it less conspicuous.

\section{Nasal tip}

If the nasal tip distortion is minimal, a closed or an open rhinoplasty approach can be used. The extra fibrofatty residuum is removed. It is imperative to reposition the lower lateral cartilages, as they could be splayed from the IH. Care also should be taken to leave some fibrofatty residuum in place, as the nasal tip normally has some fibrofatty tissues. If all the soft tissues have been aggressively removed, it will result in an abnormal nasal tip with a "pinched" appearance. If the nasal tip skin is stretched and grossly disfigured, then an open rhinoplasty approach with skin resection must be used. ${ }^{93-95}$ Repositioning of the lower lateral cartilages with an interdomal suture is still necessary. IHs of the alar and other area may need resection and recontouring, and care must be taken to place these incisions along the subunit borders, if possible, as is the case for the nasal dorsum.

\section{Conclusion}

Treatment of IHs incorporates a wide range of modalities, from conservative monitoring and reassurance of the parents to urgent surgical intervention for severe morbidities and complications. It is imperative to understand the different growth phases of IHs and what morbidities can be expected at each phase, so that the appropriate treatments may be given at the optimal time.

\section{Acknowledgment}

All patients gave consent for their images to be published in this review article; guardian consent was obtained for patients under the age of 18 years.

\section{Disclosure}

The authors report no conflicts of interest in this work.

\section{References}

1. Mulliken JB, Glowacki J. Hemangiomas and vascular malformations in infants and children: a classification based on endothelial characteristics. Plast Reconstr Surg. 1982;69(3):412-422.

2. Frieden IJ, Haggstrom AN, Drolet BA, et al. Infantile hemangiomas: current knowledge, future directions. Proceedings of a research workshop on infantile hemangiomas, April 7-9, 2005, Bethesda, Maryland, USA. Pediatr Dermatol. 2005;22(5):383-406.

3. Smith CJF, Friedlander SF, Guma M, Kavanaugh A, Chambers CD. Infantile hemangiomas: an updated review on risk factors, pathogenesis, and treatment. Birth Defects Res. 2017;109(11):809-815.

4. Mulliken JB, Fishman SJ, Burrows PE. Vascular anomalies. Curr Probl Surg. 2000;37(8):517-584.

5. Hemangioma Investigator Group, Haggstrom AN, Drolet BA, et al. Prospective study of infantile hemangiomas: demographic, prenatal, and perinatal characteristics. J Pediatr. 2007;150(3):291-294.

6. Amir J, Metzker A, Krikler R, Reisner SH. Strawberry hemangioma in preterm infants. Pediatr Dermatol. 1986;3(4):331-332.

7. Haggstrom AN, Drolet BA, Baselga E, et al. Prospective study of infantile hemangiomas: clinical characteristics predicting complications and treatment. Pediatrics. 2006;118(3):882-887.

8. Goelz R, Poets CF. Incidence and treatment of infantile haemangioma in preterm infants. Arch Dis Child Fetal Neonatal Ed. 2015;100(1):F85-F91.

9. Lopez Gutierrez JC, Avila LF, Sosa G, Patron M. Placental anomalies in children with infantile hemangioma. Pediatr Dermatol. 2007;24(4):353-355.

10. Munden A, Butschek R, Tom WL, et al. Prospective study of infantile haemangiomas: incidence, clinical characteristics and association with placental anomalies. Br J Dermatol. 2014;170(4):907-913.

11. Bauland CG, Smit JM, Scheffers SM, et al. Similar risk for hemangiomas after amniocentesis and transabdominal chorionic villus sampling. J Obstet Gynaecol Res. 2012;38(2):371-375.

12. Burton BK, Schulz CJ, Angle B, Burd LI. An increased incidence of haemangiomas in infants born following chorionic villus sampling (CVS). Prenat Diagn. 1995;15(3):209-214.

13. Bauland CG, Smit JM, Bartelink LR, Zondervan HA, Spauwen PH. Hemangioma in the newborn: increased incidence after chorionic villus sampling. Prenat Diagn. 2010;30(10):913-917.

14. Couto RA, Maclellan RA, Zurakowski D, Greene AK. Infantile hemangioma: clinical assessment of the involuting phase and implications for management. Plast Reconstr Surg. 2012;130(3):619-624.

15. Lee AH, Hardy KL, Goltsman D, et al. A retrospective study to classify surgical indications for infantile hemangiomas. J Plast Reconstr Aesthet Surg. 2014;67(9):1215-1221.

16. Baselga E, Roe E, Coulie J, et al. Risk factors for degree and type of sequelae after involution of untreated hemangiomas of infancy. JAMA Dermatol. 2016;152(11):1239-1243.

17. Cerrati EW, O TM, Chung H, Waner M. Diode laser for the treatment of telangiectasias following hemangioma involution. Otolaryngol Head Neck Surg. 2015;152(2):239-243.

18. Chang LC, Haggstrom AN, Drolet BA, et al; Hemangioma Investigator Group. Growth characteristics of infantile hemangiomas: implications for management. Pediatrics. 2008;122(2):360-367.

19. Castrén E, Salminen P, Gissler M, Stefanovic V, Pitkäranta A, Klockars T. Risk factors and morbidity of infantile haemangioma: preterm birth promotes ulceration. Acta Paediatr. 2016;105(8):940-945.

20. Huang SA, Tu HM, Harney JW, et al. Severe hypothyroidism caused by type 3 iodothyronine deiodinase in infantile hemangiomas. $N$ Engl JMed. 2000;343(3):185-189.

21. Gnarra M, Behr G, Kitajewski A, et al. History of the infantile hepatic hemangioma: from imaging to generating a differential diagnosis. World J Clin Pediatr. 2016;5(3):273-280. 
22. Christison-Lagay ER, Burrows PE, Alomari A, et al. Hepatic hemangiomas: subtype classification and development of a clinical practice algorithm and registry. J Pediatr Surg. 2007;42(1):62-67; discussion 67-68.

23. Ji Y, Chen S, Xiang B, et al. Clinical features and management of multifocal hepatic hemangiomas in children: a retrospective study. Sci Rep. 2016;6:31744.

24. Barrio VR, Drolet BA. Treatment of hemangiomas of infancy. Dermatol Ther. 2005;18(2):151-159.

25. Garzon MC, Frieden IJ. Hemangiomas: when to worry. Pediatr Ann. 2000;29(1):58-67.

26. Chamlin SL, Haggstrom AN, Drolet BA, et al. Multicenter prospective study of ulcerated hemangiomas. J Pediatr. 2007;151(6):684-689, 689.e1

27. Connelly EA, Viera M, Price C, Waner M. Segmental hemangioma of infancy complicated by life-threatening arterial bleed. Pediatr Dermatol. 2009;26(4):469-472.

28. Li Y, Hu Y, Li H, Deng L. Successful treatment of ulcerated hemangiomas with a dual-wavelength 595- and 1064-nm laser system. J Dermatolog Treat. 2016;27(6):562-567.

29. Ting M, Roseby R, McAdam C. Subglottic infantile haemangioma: a rare but important consideration in young infants presenting with stridor. J Paediatr Child Health. 2016;52(12):1111-1113.

30. Chun RH, McCormick ME, Martin T, Drolet BA, Kerschner JE. Office-based subglottic evaluation in children with risk of subglottic hemangioma. Ann Otol Rhinol Laryngol. 2016;125(4):273-276.

31. Orlow SJ, Isakoff MS, Blei F. Increased risk of symptomatic hemangiomas of the airway in association with cutaneous hemangiomas in a "beard" distribution. J Pediatr. 1997;131(4):643-646.

32. Sherrington CA, Sim DK, Freezer NJ, Robertson CF. Subglottic haemangioma. Arch Dis Child. 1997;76(5):458-459.

33. Spence-Shishido AA, Good WV, Baselga E, Frieden IJ. Hemangiomas and the eye. Clin Dermatol. 2015;33(2):170-182.

34. Ceisler EJ, Santos L, Blei F. Periocular hemangiomas: what every physician should know. Pediatr Dermatol. 2004;21(1):1-9.

35. Drolet BA, Dohil M, Golomb MR, et al. Early stroke and cerebral vasculopathy in children with facial hemangiomas and PHACE association. Pediatrics. 2006;117(3):959-964.

36. Haggstrom AN, Garzon MC, Baselga E, et al. Risk for PHACE syndrome in infants with large facial hemangiomas. Pediatrics. 2010;126(2): e418-e426.

37. Hess CP, Fullerton HJ, Metry DW, et al. Cervical and intracranial arterial anomalies in 70 patients with PHACE syndrome. AJNR Am J Neuroradiol. 2010;31(10):1980-1986.

38. Heyer GL, Millar WS, Ghatan S, Garzon MC. The neurologic aspects of PHACE: case report and review of the literature. Pediatr Neurol. 2006;35(6):419-424.

39. Siegel DH, Tefft KA, Kelly T, et al. Stroke in children with posterior fossa brain malformations, hemangiomas, arterial anomalies, coarctation of the aorta and cardiac defects, and eye abnormalities (PHACE) syndrome: a systematic review of the literature. Stroke. 2012;43(6): 1672-1674.

40. Metry D, Heyer G, Hess C, et al; PHACE Syndrome Research Conference. Consensus statement on diagnostic criteria for PHACE syndrome. Pediatrics. 2009;124(5):1447-1456.

41. Metry DW, Haggstrom AN, Drolet BA, et al. A prospective study of PHACE syndrome in infantile hemangiomas: demographic features, clinical findings, and complications. Am J Med Genet A. 2006;140(9): 975-986.

42. Dijkema EJ, Leiner T, Grotenhuis HB. Diagnosis, imaging and clinical management of aortic coarctation. Heart. 2017;103(15): 1148-1155.

43. Jack AS, Chow MM, Fiorillo L, Chibuk T, Yager JY, Mehta V. Bilateral pial synangiosis in a child with PHACE syndrome. J Neurosurg Pediatr. 2016;17(1):70-75

44. Chinnadurai S, Sathe NA, Surawicz T. Laser treatment of infantile hemangioma: a systematic review. Lasers Surg Med. 2016;48(3):221-233.
45. Kessels JP, Hamers ET, Ostertag JU. Superficial hemangioma: pulsed dye laser versus wait-and-see. Dermatol Surg. 2013;39(3 pt 1):414-421.

46. Batta K, Goodyear HM, Moss C, Williams HC, Hiller L, Waters R. Randomised controlled study of early pulsed dye laser treatment of uncomplicated childhood haemangiomas: results of a 1-year analysis. Lancet. 2002;360(9332):521-527.

47. McCuaig CC, Cohen L, Powell J, et al. Therapy of ulcerated hemangiomas. J Cutan Med Surg. 2013;17(4):233-242.

48. Bruscino N, Bonan P, Cannarozzo G, Moretti S, Lotti T, Campolmi P. Laser use in infantile hemangiomas, when and how. Dermatol Ther. 2012;25(4):314-321.

49. Re M, Forte V, Berardi C, Mallardi V. Role of endoscopic CO2 laser surgery in the treatment of congenital infantile subglottic hemangioma. Experience in the department of otolaryngology, "Sick Children Hospital", Toronto, Canada. Acta Otorhinolaryngol Ital. 2003;23(3):175-179.

50. Claros A, Fokouo JV, Roqueta C, Claros P. Management of subglottic hemangiomas with carbon dioxide laser: our 25-year experience and comparison with the literature. Int $J$ Pediatr Otorhinolaryngol. 2015;79(12):2003-2007.

51. Kacker A, April M, Ward RF. Use of potassium titanyl phosphate (KTP) laser in management of subglottic hemangiomas. Int J Pediatr Otorhinolaryngol. 2001;59(1):15-21.

52. Fu CH, Lee LA, Fang TJ, Wong KS, Li HY. Endoscopic Nd:YAG laser therapy of infantile subglottic hemangioma. Pediatr Pulmonol. 2007;42(1):89-92.

53. Drolet BA, Frommelt PC, Chamlin SL, et al. Initiation and use of propranolol for infantile hemangioma: report of a consensus conference. Pediatrics. 2013;131(1):128-140.

54. Leaute-Labreze C, Dumas de la Roque E, Hubiche T, Boralevi F, Thambo JB, Taieb A. Propranolol for severe hemangiomas of infancy. $N$ Engl J Med. 2008;358(24):2649-2651.

55. Sans V, Dumas de la Roque E, Berge J, et al. Propranolol for severe infantile hemangiomas: follow-up report. Pediatrics. 2009;124(3):e423-e431.

56. Buckmiller L, Dyamenahalli U, Richter GT. Propranolol for airway hemangiomas: case report of novel treatment. Laryngoscope. 2009;119(10):2051-2054.

57. Jephson CG, Manunza F, Syed S, Mills NA, Harper J, Hartley BE. Successful treatment of isolated subglottic haemangioma with propranolol alone. Int J Pediatr Otorhinolaryngol. 2009;73(12):1821-1823.

58. Denoyelle F, Leboulanger N, Enjolras O, Harris R, Roger G, Garabedian EN. Role of propranolol in the therapeutic strategy of infantile laryngotracheal hemangioma. Int J Pediatr Otorhinolaryngol. 2009;73(8): 1168-1172.

59. Fuchsmann C, Quintal MC, Giguere C, et al. Propranolol as first-line treatment of head and neck hemangiomas. Arch Otolaryngol Head Neck Surg. 2011;137(5):471-478.

60. Peridis S, Pilgrim G, Athanasopoulos I, Parpounas K. A meta-analysis on the effectiveness of propranolol for the treatment of infantile airway haemangiomas. Int J Pediatr Otorhinolaryngol. 2011;75(4):455-460.

61. Hogeling M, Adams S, Wargon O. A randomized controlled trial of propranolol for infantile hemangiomas. Pediatrics. 2011;128(2):e259-e266.

62. Marqueling AL, Oza V, Frieden IJ, Puttgen KB. Propranolol and infantile hemangiomas four years later: a systematic review. Pediatr Dermatol. 2013;30(2):182-191.

63. Brazzelli V, Giorgini C, Barruscotti S, et al. Efficacy of propranolol for cutaneous hemangiomas in premature children. G Ital Dermatol Venereol. 2016;151(5):485-491.

64. Metry D, Frieden IJ, Hess C, et al. Propranolol use in PHACE syndrome with cervical and intracranial arterial anomalies: collective experience in 32 infants. Pediatr Dermatol. 2013;30(1):71-89.

65. Blanchet C, Nicollas R, Bigorre M, Amedro P, Mondain M. Management of infantile subglottic hemangioma: acebutolol or propranolol? Int J Pediatr Otorhinolaryngol. 2010;74(8):959-961.

66. Abarzua-Araya A, Navarrete-Dechent CP, Heusser F, Retamal J, ZegpiTrueba MS. Atenolol versus propranolol for the treatment of infantile hemangiomas: a randomized controlled study. J Am Acad Dermatol. 2014;70(6):1045-1049. 
67. Chakkittakandiyil A, Phillips R, Frieden IJ, et al. Timolol maleate $0.5 \%$ or $0.1 \%$ gel-forming solution for infantile hemangiomas: a retrospective, multicenter, cohort study. Pediatr Dermatol. 2012;29(1):28-31.

68. Zarem HA, Edgerton MT. Induced resolution of cavernous hemangiomas following prednisolone therapy. Plast Reconstr Surg. 1967;39(1):76-83.

69. Pope E, Krafchik BR, Macarthur C, et al. Oral versus high-dose pulse corticosteroids for problematic infantile hemangiomas: a randomized, controlled trial. Pediatrics. 2007;119(6):e1239-e1247.

70. Money S. The risks of chronic corticosteroid exposure. J Pain Palliat Care Pharmacother. 2017;31(2):160-161.

71. Poetke M, Philipp C, Berlien HP. Flashlamp-pumped pulsed dye laser for hemangiomas in infancy: treatment of superficial vs mixed hemangiomas. Arch Dermatol. 2000;136(5):628-632.

72. Boon LM, MacDonald DM, Mulliken JB. Complications of systemic corticosteroid therapy for problematic hemangioma. Plast Reconstr Surg. 1999;104(6):1616-1623.

73. Bauman NM, McCarter RJ, Guzzetta PC, et al. Propranolol vs prednisolone for symptomatic proliferating infantile hemangiomas: a randomized clinical trial. JAMA Otolaryngol Head Neck Surg. 2014;140(4):323-330.

74. White CW, Sondheimer HM, Crouch EC, Wilson H, Fan LL. Treatment of pulmonary hemangiomatosis with recombinant interferon alfa-2a. N Engl J Med. 1989;320(18):1197-1200.

75. Brouty-Boye D, Zetter BR. Inhibition of cell motility by interferon. Science. 1980;208(4443):516-518.

76. Ezekowitz A, Mulliken J, Folkman J. Interferon alpha therapy of haemangiomas in newborns and infants. Br J Haematol. 1991;79(suppl 1):67-68.

77. Rohatiner AZ, Prior P, Burton A, Balkwill F, Lister TA. Central nervous system toxicity of interferon. Prog Exp Tumor Res. 1985;29:197-202.

78. Barlow CF, Priebe CJ, Mulliken JB, et al. Spastic diplegia as a complication of interferon Alfa-2a treatment of hemangiomas of infancy. J Pediatr. 1998;132(3 pt 1):527-530.

79. Yeh I, Bruckner AL, Sanchez R, Jeng MR, Newell BD, Frieden IJ. Diffuse infantile hepatic hemangiomas: a report of four cases successfully managed with medical therapy. Pediatr Dermatol. 2011;28(3):267-275.

80. Marsciani A, Pericoli R, Alaggio R, Brisigotti M, Vergine G. Massive response of severe infantile hepatic hemangioma to propanolol. Pediatr Blood Cancer. 2009;54(1):176.
81. Garzon MC, Weitz N, Powell J. Vascular anomalies: differential diagnosis and mimickers. Semin Cutan Med Surg. 2016;35(3):170-176.

82. North PE, Waner M, Mizeracki A, Mihm MC Jr. GLUT1: a newly discovered immunohistochemical marker for juvenile hemangiomas. Hum Pathol. 2000;31(1):11-22.

83. Wu JK, Ascherman JA. Vascular anomalies. In: Guyuron B, Eriksson E, Persing JA, et al., editors. Plastic Surgery: Indications and Practice. Vol. 1. 1st. ed. China: Saunders Elsevier; 2009:761-777.

84. Girard C, Bigorre M, Guillot B, Bessis D. PELVIS Syndrome. Arch Dermatol. 2006;142(7):884-888.

85. Tanzi EL, Lupton JR, Alster TS. Lasers in dermatology: four decades of progress. J Am Acad Dermatol. 2003;49(1):1-31; quiz 31-34.

86. Anderson RR, Parrish JA. The optics of human skin. J Invest Dermatol. 1981;77(1):13-19.

87. Al Buainian H, Verhaeghe E, Dierckxsens L, Naeyaert JM. Early treatment of hemangiomas with lasers. A review. Dermatology. 2003;206(4):370-373.

88. Zvulunov A, McCuaig C, Frieden IJ, et al. Oral propranolol therapy for infantile hemangiomas beyond the proliferation phase: a multicenter retrospective study. Pediatr Dermatol. 2011;28(2):94-98.

89. Mulliken JB, Rogers GF, Marler JJ. Circular excision of hemangioma and purse-string closure: the smallest possible scar. Plast Reconstr Surg. 2002;109(5):1544-1554; discussion 1555.

90. Wu JK, Rohde CH. Purse-string closure of hemangiomas: early results of a follow-up study. Ann Plast Surg. 2009;62(5):581-585.

91. Chang CS, Wong A, Rohde CH, Ascherman JA, Wu JK. Management of lip hemangiomas: minimizing peri-oral scars. J Plast Reconstr Aesthet Surg. 2012;65(2):163-168

92. Li WY, Chaudhry O, Reinisch JF. Guide to early surgical management of lip hemangiomas based on our experience of 214 cases. Plast Reconstr Surg. 2011;128(5):1117-1124.

93. Arneja JS, Chim H, Drolet BA, Gosain AK. The Cyrano nose: refinements in surgical technique and treatment approach to hemangiomas of the nasal tip. Plast Reconstr Surg. 2010;126(4):1291-1299.

94. McCarthy JG, Borud LJ, Schreiber JS. Hemangiomas of the nasal tip. Plast Reconstr Surg. 2002;109(1):31-40.

95. Warren SM, Longaker MT, Zide BM. The subunit approach to nasal tip hemangiomas. Plast Reconstr Surg. 2002;109(1):25-30.
Pediatric Health, Medicine and Therapeutics

\section{Publish your work in this journal}

Pediatric Health, Medicine and Therapeutics is an international, peerreviewed, open access journal publishing original research, reports, editorials, reviews and commentaries. All aspects of health maintenance, preventative measures and disease treatment interventions are addressed within the journal. Practitioners from all disciplines are invited to submit

\section{Dovepress}

their work as well as healthcare researchers and patient support groups The manuscript management system is completely online and includes a very quick and fair peer-review system. Visit http://www.dovepress.com/ testimonials.php to read real quotes from published authors. 